\title{
Alemtuzumab in the treatment of multiple sclerosis
}

\author{
This article was published in the following Dove Press journal: \\ Journal of Inflammation Research \\ 12 February 2014 \\ Number of times this article has been viewed
}

\section{Óscar Fernandez}

Institute of Clinical Neuroscience, Neurology Department, Hospital Regional Universitario Carlos Haya, FIMABIS, Malaga, Spain
Correspondence: Óscar Fernandez Institute of Clinical Neuroscience, Neurology Department, IBIMA (Instituto de Investigación Biomédica de Málaga), Hospital Universitario Regional de Málaga - Universidad de Málaga Avda, de Carlos Haya sn, 29010 Málaga, Spain

Tel +34 95 ।29| I 35

Fax +34 $95 \quad$ I29| 157

Email oscar.fernandez.sspa@

juntadeandalucia.es
Abstract: Alemtuzumab (formerly known as Campath-1H) has recently been approved by the European Medicines Agency for highly-active, relapsing-remitting multiple sclerosis (MS). The molecule targets the CD52 surface glycoprotein on certain T cells and B cells and is thought to exert its effect in MS through a "resetting" of the lymphocyte population. Approval was granted on the strength of two pivotal studies, Comparison of Alemtuzumab and Rebif ${ }^{\mathbb{B}}$ Efficacy in Multiple Sclerosis (CARE-MS)-1 in the first-line setting and CARE-MS-2 in patients who had failed first-line therapy. In both studies, alemtuzumab significantly reduced the relapse rate compared to the comparator, interferon beta-1a (44 $\mu \mathrm{g}$ ) given subcutaneously three-times per week $\left(\right.$ Rebif $\left.^{\circledR}\right)$. In the first-line study, alemtuzumab was also found to significantly reduce the number of patients with sustained progression compared to interferon beta-1a therapy. Autoimmune disorders represent the major side effect of alemtuzumab therapy although they can be managed by careful monitoring and early treatment. Overall, alemtuzumab is likely to be a valuable addition to the neurologist's armamentarium for the treatment of relapsing-remitting MS.

Keywords: alemtuzumab, multiple sclerosis, new therapies, interferon beta-1a, monoclonal antibody, treatment

\section{Introduction}

Alemtuzumab (formerly known as Campath-1H) is a recombinant DNA-derived, immunoglobulin 1 kappa humanized monoclonal antibody of approximately $150 \mathrm{kD}$, with a human variable framework and constant regions and complementary-determining regions from a murine monoclonal antibody. The antibody exercises its biological effect by binding to CD52, a surface glycoprotein found in abundance on certain T cells and B cells, ${ }^{1}$ whereupon it induces antibody-dependent cellular cytolysis and complement-mediated lysis.

The molecule was originally developed and approved as an anticancer agent in the treatment of B-cell chronic lymphocytic leukemia, ${ }^{2}$ although there have also been reports of off-label use in autoimmune diseases such as rheumatoid arthritis, ${ }^{3}$ refractory autoimmune thrombocytopenia purpura, ${ }^{4}$ and systemic vasculitis. ${ }^{5,6}$ After promising results in early open-label clinical trials, clinical development of alemtuzumab was undertaken in multiple sclerosis (MS), ${ }^{7}$ culminating in the recent approval of the drug by the European Medicines Agency for the treatment of adult patients with relapsingremitting MS with active disease defined by clinical or imaging features. ${ }^{8}$

After an overview of the mechanism of action, this review covers the clinical experience to date in MS, with special focus on the two Phase III pivotal studies that formed the cornerstone of the clinical development program. The potentially serious 
but readily manageable safety issues are presented. Finally, the place of alemtuzumab among the emerging MS therapies is briefly discussed.

\section{Clinical pharmacology and presumed mechanism of action}

In an oncology setting, alemtuzumab is typically administered over a period of several weeks, ${ }^{9}$ whereas in an MS setting, alemtuzumab is administered as two short courses (pulses). In the first course, $12 \mathrm{mg} /$ day is administered for 5 consecutive days ( $60 \mathrm{mg}$ total dose); in the second course, $12 \mathrm{mg} /$ day for 3 consecutive days ( $36 \mathrm{mg}$ total dose) is administered 12 months after the initial treatment course. ${ }^{10}$

As with many MS treatments, the exact mechanism by which alemtuzumab exerts its effect in MS is not well known. The mean terminal-phase half-life of alemtuzumab is 6.1 days, ${ }^{11}$ yet the effects of treatment persist for much longer. The overall consensus is that the benefit of alemtuzumab in MS is derived from a "resetting" of the immune system. ${ }^{12}$ In particular, changes in the number, proportions, and properties of some lymphocyte subsets, enrichment of regulatory $\mathrm{T}$ cell subsets and $\mathrm{T}$ and $\mathrm{B}$ lymphocytes, and transient effects on components of innate immunity such as neutrophils, macrophages, and natural killer cells are thought to play a role. ${ }^{8}$ To investigate the dynamics of the lymphocyte counts, Cox et $\mathrm{al}^{13}$ administered a single pulse of alemtuzumab to 16 patients and prospectively followed these patients for 12 months. After initial depletion, the authors observed two phases of lymphocyte reconstitution, with B lymphocyte counts largely returning to pretreatment values after 3 months, while T cell recovery was much more protracted. By month 12, T cell counts were still only $47 \%$ of pretreatment values, with the depletion attributable largely to depleted CD4+ and CD8+ T cell counts. This asymmetric reconstitution could be related to the mechanism of action and efficacy of this drug in MS over time.

Although the reduction in relapses is thought to ultimately slow disability progression, it has also been speculated that alemtuzumab may exercise a long-term reparative and neurogenerative potential. Thus Jones et $\mathrm{al}^{14}$ attempted to explain why disability improved in some patients treated with alemtuzumab and why there was no disease activity before or during the Phase II Campath-1H in Multiple Sclerosis (CAMMS) 223 trial in a post-hoc analysis. ${ }^{15}$ This was in contrast to similar patients treated with interferon beta-1a, who showed no such improvement. The authors speculated that this effect could be due to induction of certain potentially beneficial factors and showed that these factors were indeed produced in cell cultures exposed to alemtuzumab after stimulation with myelin basic protein.

\section{Phase III clinical experience}

The clinical development program for alemtuzumab in the indication of MS culminated in two randomized, rater-blinded, pivotal Phase III studies, Comparison of Alemtuzumab and Rebif ${ }^{\circledR}$ Efficacy in Multiple Sclerosis (CARE-MS)-1 and CARE-MS-2. ${ }^{16,17}$ These two studies compared alemtuzumab treatment with interferon beta-1a $\left(\right.$ Rebif $\left.^{\circledR}\right)$, and in both cases, the coprimary efficacy endpoints were relapse rate and time to 6-month sustained accumulation of disability (measured using the Expanded Disability Status Scale [EDSS]) 24 months after the first treatment administration. The two studies ran almost in parallel, thus patients were recruited between September 2007 and April 2009 in the case of the CARE-MS-1 study and between October 2007 and September 2009 in the case of the CAREMS-2 study. The main difference between the studies was that the CARE-MS-1 study enrolled patients who had not received prior treatment for MS (except corticosteroids), while the CARE-MS-2 study enrolled patients who had failed previous MS treatment. A detailed comparison of the inclusion criteria is shown in Table 1. Patients in the CARE-MS-2 trial could potentially have longer-standing disease (up to 10 years instead of 5 years) and more advanced disability (EDSS up to 5.0 instead of up to 3.0). Another difference was that while patients in the CARE-MS-1 trial were randomized 2:1 to receive either alemtuzumab $12 \mathrm{mg}$ or subcutaneous interferon beta-1a $44 \mu \mathrm{g}$ three times a week, patients in the CARE-MS-2 trial were randomized 2:2:1 to alemtuzumab $12 \mathrm{mg}$, alemtuzumab $24 \mathrm{mg}$, or subcutaneous interferon beta-1a $44 \mu \mathrm{g}$ three times a week. However, the high-dose alemtuzumab arm was discontinued early to accelerate recruitment, which had been hindered by safety concerns about the higher dose. After this point, patients continued to be randomized 2:1 to alemtuzumab $12 \mathrm{mg}$ or interferon beta-1a.

\section{Patient characteristics}

Unsurprisingly, given the eligibility criteria, patients in the CARE-MS-2 trial were slightly older and had a longer disease duration (Table 2). Within each study, the baseline characteristics were comparable between comparator and alemtuzumab. Consistent with the eligibility criteria, all patients in the CARE-MS-2 trial had received previous MS drugs (450/628 [71.7\%] had received one prior treatment and 133/628 [21.2\%] had received two prior treatments, excluding the patients randomized to alemtuzumab $24 \mathrm{mg}$ ). 
Table I Eligibility criteria for the CARE-MS-I and CARE-MS-2 trials

CARE-MS-I (alemtuzumab as first-line treatment) ${ }^{16}$ Inclusion criteria

- Diagnosis of MS and cranial MRI scan demonstrating white matter lesions attributable to MS within 5 years

- Onset of MS symptoms within 5 years

- EDSS score 0.0-3.0

- $\geq 2$ MS relapses within 24 months, with $\geq 1$ relapse within 12 month

Main exclusion criteria

- Prior therapy for MS other than corticosteroids

- Exposure to immunosuppressive or immunomodulatory agents other than systemic corticosteroid treatment

- Previous treatment with a monoclonal antibody for any reason

- Any progressive form of MS
- Age 18-50 years, either sex

CARE-MS-2 (alemtuzumab after failure of disease-modifying therapy) ${ }^{17}$

Inclusion criteria

- Age 18-55 years, either sex

- Diagnosis of MS and cranial MRI scan demonstrating white matter lesions attributable to MS

- Onset of MS symptoms within 10 years

- EDSS score 0.0-5.0

- $\geq 2$ MS relapses within 24 months, with $\geq 1$ relapse within 12 months

- $\geq$ I MS relapse during treatment with a beta interferon therapy or glatiramer acetate after having been on that therapy for at least 6 months within 10 years

Main exclusion criteria

- Previous treatment with alemtuzumab

- Previous treatment with any investigational drug

- Treatment with natalizumab, methotrexate, azathioprine or cyclosporine in the past 6 months

- Previous treatment with mitoxantrone, cyclophosphamide, cladribine, rituximab, or any other immunosuppressive or cytotoxic therapy (other than steroid treatment)

- Any progressive form of MS

Note: Data from Cohen et al ${ }^{16}$ and Coles et al. ${ }^{17}$

Abbreviations: EDSS, expanded disability status scale; MRI, magnetic resonance imaging; MS, multiple sclerosis; CARE-MS, Comparison of Alemtuzumab and Rebif ${ }^{\circledast}$ Efficacy in Multiple Sclerosis.

The most frequently reported prior MS drug was interferon beta-1a in the subcutaneous formulation (219/628 [34.9\%]) or intramuscular formulation (166/628 [26.4\%]), interferon beta-1b (217/628 [34.6\%]), and glatiramer acetate $(215 / 628[34.2 \%])$.

\section{Efficacy outcomes}

The main efficacy outcomes are presented in Table 3. For the coprimary endpoint of relapse rates, there was a highly significant treatment effect in favor of alemtuzumab in both studies, with risk reduction of 55\% in the CARE-MS-1 study and of $49 \%$ in the CARE-MS-2 study. In the case of the coprimary disability endpoint (sustained progression confirmed over 6 months), significant differences between treatment arms were only observed in the CARE-MS-2 study (risk reduction of $42 \%$ ).

At this point, it is perhaps worth discussing the choice of comparator in these studies. Unlike most previous pivotal MS studies, an active comparator and not placebo was used in the study design. The comparator chosen was subcutaneous interferon beta-1a. A recent Cochrane review found that natalizumab and subcutaneous interferon beta-1a were superior to other treatments in terms of preventing relapses in patients with relapsing disease. ${ }^{18}$ The odds ratio for relapses for interferon-beta 1a as compared to placebo over 24 months was 0.32 (95\% confidence interval [CI] 0.24-0.45).

Table 2 Baseline characteristics of patients enrolled in the CARE-MS-I and CARE-MS-2 trials

\begin{tabular}{|c|c|c|c|c|}
\hline & \multicolumn{2}{|c|}{$\begin{array}{l}\text { CARE-MS-I (alemtuzumab as } \\
\text { first-line treatment) }\end{array}$} & \multicolumn{2}{|c|}{$\begin{array}{l}\text { CARE-MS-2 (alemtuzumab after } \\
\text { failure of disease-modifying therapy) }{ }^{17, a}\end{array}$} \\
\hline & $\begin{array}{l}\text { IFN beta- Ia } \\
(n=\mid 87)\end{array}$ & $\begin{array}{l}\text { Alemtuzumab } \\
\text { I } 2 \mathrm{mg} \\
(\mathrm{n}=376)\end{array}$ & $\begin{array}{l}\text { IFN beta- } I \text { a } \\
(n=202)\end{array}$ & $\begin{array}{l}\text { Alemtuzumab } \\
\text { I } 2 \mathrm{mg} \\
(\mathrm{n}=426)\end{array}$ \\
\hline Age, years & $33.2 \pm 8.5$ & $33.0 \pm 8.0$ & $35.8 \pm 8.8$ & $34.8 \pm 8.4$ \\
\hline Sex, female & $122(65 \%)$ & $243(65 \%)$ & $|3|(65 \%)$ & $281(66 \%)$ \\
\hline Mean EDSS & $2.0 \pm 0.8$ & $2.0 \pm 0.8$ & $2.7 \pm 1.2$ & $2.7 \pm 1.3$ \\
\hline Mean disease duration & $2.0 \pm 1.3$ & $2.1 \pm 1.4$ & $4.7 \pm 2.9$ & $4.5 \pm 2.7$ \\
\hline $\begin{array}{l}\text { Mean number of relapses in } \\
\text { previous year }\end{array}$ & $1.8 \pm 0.8$ & $1.8 \pm 0.8$ & $1.5 \pm 0.8$ & $1.7 \pm 0.9$ \\
\hline Mean number of Gd-enhancing & $2.2 \pm 4.9$ & $2.3 \pm 5.1$ & $2.1 \pm 5.0$ & $2.3 \pm 6.0$ \\
\hline TI-weighted lesions & & & & \\
\hline Mean number of $\mathrm{T} 2$-hyperintense lesions & $7.3 \pm 9.9$ & $7.4 \pm 9.0$ & $9.0 \pm 10.4$ & $9.9 \pm 12.3$ \\
\hline
\end{tabular}

Notes: Data presented as mean \pm standard deviation unless otherwise stated; alemtuzumab $24 \mathrm{mg}$ arm not shown, as not included in primary efficacy analysis. Data from Cohen et al ${ }^{16}$ and Coles et al. ${ }^{17}$

Abbreviations: EDSS, expanded disability status scale; Gd, gadolinium; IFN, interferon; CARE-MS, Comparison of Alemtuzumab and Rebif ${ }^{\circledR}$ Efficacy in Multiple Sclerosis. 
Table 3 Efficacy outcomes of patients enrolled in the CARE-MS-I and CARE-MS-2 trials

\begin{tabular}{|c|c|c|c|c|c|c|}
\hline & \multicolumn{3}{|c|}{$\begin{array}{l}\text { CARE-MS-I (alemtuzumab as } \\
\text { first-line treatment) }{ }^{16}\end{array}$} & \multicolumn{3}{|c|}{$\begin{array}{l}\text { CARE-MS-2 (alemtuzumab after failure } \\
\text { of disease-modifying therapy) }\end{array}$} \\
\hline & $\begin{array}{l}\text { IFN beta- Ia } \\
(n=\mid 87)\end{array}$ & $\begin{array}{l}\text { Alemtuzumab } \\
12 \mathrm{mg} \\
(\mathrm{n}=376)\end{array}$ & $P$ & $\begin{array}{l}\text { IFN beta-I a } \\
(n=202)\end{array}$ & $\begin{array}{l}\text { Alemtuzumab } \\
\text { I } 2 \mathrm{mg} \\
(\mathrm{n}=426)\end{array}$ & $P$ \\
\hline \multicolumn{7}{|l|}{ Relapses } \\
\hline Patients with relapse & $75(40 \%)$ & $82(22 \%)$ & & $104(53 \%)$ & 147 (35\%) & \\
\hline Rate ratio $(95 \% \mathrm{Cl})$ & & $0.45(0.320 .63)$ & $<0.0001$ & & 0.5 I $(0.39-0.65)$ & $<0.0001$ \\
\hline Risk reduction & & $55 \%$ & & & $49 \%$ & \\
\hline Yearly relapse rate $(95 \% \mathrm{Cl})$ & $0.39(0.29-0.53)$ & $0.18(0.13-0.23)$ & & $0.52(0.4 I-0.66)$ & $0.26(0.21-0.33)$ & \\
\hline Relapse-free patients (95\% Cl) & $58.7 \%(5 I .1 \%-65.5 \%)$ & $77.6 \%(72.9 \%-81.6 \%)$ & $<0.0001$ & $46.7 \%(39.5 \%-53.5 \%)$ & $65.4 \%(60.7 \%-69.7 \%)$ & $<0.000$ I \\
\hline \multicolumn{7}{|l|}{ Disability } \\
\hline $\begin{array}{l}\text { Patients with sustained } \\
\text { accumulation }\end{array}$ & $20(11 \%)$ & $30(8 \%)$ & & $40(20 \%)$ & $54(13 \%)$ & \\
\hline $\begin{array}{l}\text { Percentage of patients } \\
(95 \% \mathrm{Cl})^{\mathrm{b}}\end{array}$ & $11.1 \%(7.3 \%-16.7 \%)$ & $8.0 \%(5.7 \%-11.2 \%)$ & 0.22 & $21.1 \%(16.0-27.7)$ & $12.7 \%(9.9 \%-16.3 \%)$ & \\
\hline Hazard ratio $(95 \% \mathrm{Cl})$ & & $0.70(0.40-1.23)$ & & & $0.58(0.38-0.87)$ & \\
\hline Risk reduction & & $30 \%$ & & & $42 \%$ & 0.0084 \\
\hline $\begin{array}{l}\text { Mean change in EDSS } \\
\text { from baseline }(95 \% \mathrm{Cl})\end{array}$ & $-0.14(-0.29-0.01)$ & $-0.14(-0.25-0.02)$ & 0.97 & $0.24(0.07-0.4 \mathrm{I})$ & $-0.17(-0.29$ to -0.05$)$ & $<0.0001$ \\
\hline $\begin{array}{l}\text { Mean change in MSFC } \\
\text { from baseline }\end{array}$ & 0.07 & 0.15 & 0.01 & -0.04 & 0.08 & 0.002 \\
\hline MRI & & & & & & \\
\hline $\begin{array}{l}\text { Patients with new } \\
\text { or enlarging }\end{array}$ & $99 / 172(58 \%)$ & I76/363 (48\%) & 0.04 & $127 / \mid 87$ (68\%) & I86/403 (46\%) & $<0.000$ I \\
\hline T2-hyperintense lesions & & & & & & \\
\hline $\begin{array}{l}\text { Patients with Gd-enhancing } \\
\text { lesions at } 24 \text { months }\end{array}$ & $34 / 178$ (19\%) & $26 / 366(7 \%)$ & $<0.0001$ & $44 / 190(23 \%)$ & $38 / 410(9 \%)$ & $<0.000$ I \\
\hline
\end{tabular}

Notes: aConfirmed over 6 months; ${ }^{\text {} K a p l a n-M e i e r ~ e s t i m a t i o n . ~ D a t a ~ f r o m ~ C o h e n ~ e t ~ a l ~}{ }^{16}$ and Coles et al. ${ }^{17}$

Abbreviations: $\mathrm{Cl}$, confidence interval; EDSS, expanded disability status scale; Gd, gadolinium; IFN, interferon; MRI, magnetic resonance imaging; MSFC, multiple sclerosis functional composite; P, P-value; CARE-MS, Comparison of Alemtuzumab and Rebif ${ }^{\circledR}$ Efficacy in Multiple Sclerosis.

In addition, both natalizumab and subcutaneous interferon beta-1a were also suggested to have support for a moderate protective effect against disability progression, though the evidence was less convincing. Moreover, subcutaneous interferon beta-1a was the only traditional disease-modifying therapy shown to reduce disability progression in an older systematic review published in $2002,{ }^{19}$ and in a head-to-head trial of high-dose subcutaneous interferon beta-1a $(44 \mu \mathrm{g})$ and intramuscular interferon beta-1a; the high-dose subcutaneous regimen was shown to be superior to the intramuscular regimen. ${ }^{20,21}$ Subcutaneous interferon beta-1a would therefore appear to be an appropriate choice of comparator in the firstline study, as natalizumab would not have been authorized in these patients. Switching from low-dose to high-dose subcutaneous interferon beta-1a has shown to be of benefit, ${ }^{21}$ and thus high-dose subcutaneous interferon beta-1a would appear to be a valid choice of comparator in the second-line CARE-MS-2 study.

In the comparator group of the CARE-MS-1 study, the EDSS decreased from baseline $(-0.14)$, whereas an increase of 0.24 was seen in the same group in the CARE-MS-2 study (patients who had failed first-line treatment). The unexpected improvement in EDSS (rather than a slowing in progression) in the comparator group of the CARE-MS-1 study may explain in part why alemtuzumab failed to meet the disability endpoint in the CARE-MS-1 trial. In addition, the low baseline EDSS would also have made it more difficult to detect differences in changes from baseline.

As the authors of the CARE-MS-2 trial note, "no Phase III monotherapy trial has previously shown superior efficacy on EDSS disability measures against an active comparator". ${ }^{17}$ The caveat is that since the CARE trials were initiated, natalizumab has become established as a widely used second-line treatment in patients who fail first-line treatment. Without head-to-head trials, it is impossible to draw solid conclusions about the relative efficacy of alemtuzumab and natalizumab. Indeed, even indirect comparisons of the two drugs using the results from the respective pivotal trials are difficult given the differences in study design and patient population. ${ }^{12,22}$

Given the administration route and regimen of the comparator (subcutaneous interferon beta-1a) and alemtuzumab, it was not feasible to conduct a patient-blinded study. 
Nevertheless, the raters were blinded to treatment assignment (unless a masked rater was unavailable), and relapses were independently adjudicated. Sensitivity analyses on the few patients who did not have a masked rating showed no effect on the efficacy outcomes.

\section{Safety outcomes}

Overall, alemtuzumab was well-tolerated with few discontinuations due to adverse events (see Table 4). The main safety flag was autoimmune disorders. The safety of alemtuzumab is discussed in detail later in the article.

\section{Other clinical studies}

As alemtuzumab has only recently been approved for the treatment of MS, there are at present no observational studies to support the use of alemtuzumab in clinical practice. Nevertheless, prior to the Phase III studies described above, a number of open-label studies and a randomized Phase II trial were conducted.

The first trial to provide preliminary evidence of the efficacy of alemtuzumab was reported by Moreau et al. ${ }^{23}$ Seven MS patients received a 10-day intravenous course of alemtuzumab. Their disease activity was assessed by magnetic resonance imaging (MRI) 3-4 months later, and the number of lesions was found to be significantly lower compared to baseline (rate ratio of 0.15 [corrected 95\% CI $0.09-0.24], P>0.001$ ) in a "meta-analysis" of the lesions (the MRIs were recorded using different protocols).

This radiological evidence of efficacy provided encouragement for a further study by Coles et al, ${ }^{1}$ which included clinical as well as radiological endpoints. Twenty-seven patients in varying stages of disease were enrolled and assessed before and 18 months after a single pulse of alemtuzumab. The drug was found to be more effective in patients with less cerebral inflammation in the pretreatment phase. The authors suggested that the progressive disability and increasing brain atrophy could be attributed to axonal degeneration. This axonal degeneration seemed to depend in part on prior inflammation and progressed despite suppression of inflammation. As a result, subsequent development of alemtuzumab focused on relapsing-remitting MS rather than secondary progressive MS. ${ }^{24}$

Further clinical evidence of the efficacy of alemtuzumab came from another single-arm, open-label study, which included a consecutive series of 39 highly-selected patients from three different centers. ${ }^{25}$ After a mean follow-up of 1.89 years, the mean annualized relapse rate decreased from 2.48 in the period prior to baseline to 0.19

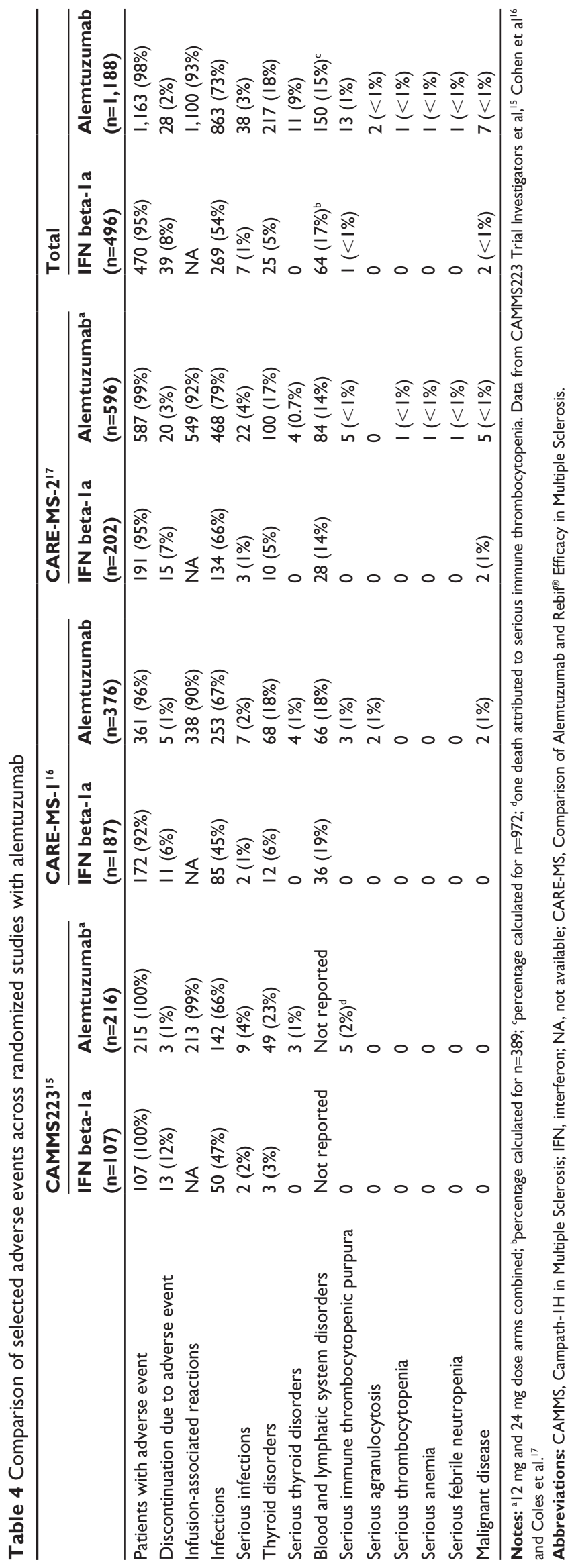


after treatment. Encouraging results for disability were also reported, with a mean change in EDSS of -0.36 for all patients and of -0.15 in those patients in follow-up for at least 12 months. In addition, 83\% had stable or improved disability following treatment. This larger series also provided the opportunity to collect more extensive safety data. In addition to infusion-related side effects, 12 patients had biochemical evidence of autoimmune dysfunction. Two patients developed thyroid disease and one patient developed autoimmune skin disease. The authors, however, suggested that these autoimmune side effects could be readily managed.

The CAMMS223 trial was a Phase II, randomized, blinded trial of previously untreated patients with early relapsing-remitting disease. ${ }^{15}$ Between December 2002 and July 2004, 334 patients (approximately two-thirds women) with a mean age of $32.1 \pm 8.4$ years and scores of 3.0 or less on the EDSS were randomized in 49 centers in Europe and the United States to interferon beta-1a $(n=111)$ for 3 years or $12 \mathrm{mg}$ alemtuzumab $(\mathrm{n}=112)$ or $24 \mathrm{mg}$ alemtuzumab (three pulses at baseline and after 12 and 24 months). The coprimary efficacy endpoints were time to sustained accumulation of disability (assessed using the EDSS) and relapse rate. Alemtuzumab therapy was suspended in September 2005 after three patients developed immune thrombocytopenic purpura (and one of these patients died) although comparator treatment and study follow-up continued. Almost all patients had received their second cycle of alemtuzumab and a quarter had received the protocol-planned third cycle. The safety aspects of this study are discussed in more detail in the following section.

Significantly fewer patients on alemtuzumab experienced sustained accumulation of disability (over 6 months) (24 [26.2\%] in the interferon beta-1a arm compared to 18 [9.0\%] in the combined alemtuzumab arms; $P<0.001$ ). In addition, the mean EDSS for patients treated with alemtuzumab decreased by 0.39 but increased by 0.38 for those treated with comparator $(P<0.001)$. Likewise, a significant treatment effect was observed in terms of relapses (41 [19.1\%] patients treated with alemtuzumab experienced a relapse compared to 45 [43.3\%] patients treated with comparator, yielding a hazard ratio of 0.26 [95\% CI 0.16-0.41, $P<0.001])$.

Efficacy was also seen in the secondary imaging endpoints. Thus, the lesion load (as measured by T2-weighted MRI) showed a significantly larger change from baseline for alemtuzumab compared to interferon beta-1a throughout the 3 years of follow-up.

\section{Safety considerations}

As mentioned earlier, autoimmune disorders associated with alemtuzumab administration had already been reported in uncontrolled studies. ${ }^{25}$ In the CAMMS223 study, immune thrombocytopenia purpura was reported in six patients who received alemtuzumab (four in the high-dose group) and one patient in the comparator group. ${ }^{15}$ One of the patients in the alemtuzumab group died of a fatal brain hemorrhage before diagnosis. The authors explained that in retrospect, cutaneous manifestations had been present for several weeks. In four of the other five patients, remission was achieved with corticosteroid or rituximab therapy. Spontaneous remission occurred in the remaining patient.

In the two Phase III studies, serious immune thrombocytic purpura was reported in eight patients (three in the CARE-MS-1 study ${ }^{16}$ and five in the care CARE-MS-2 study ${ }^{17}$ ), all of whom were receiving alemtuzumab. In all cases, the events could be managed with corticosteroids, rituximab, or intravenous immunoglobulin. As shown in Table 4, thyroid disorders were also more common among patients treated with alemtuzumab. Finally, one patient in the CARE-MS-1 study developed glomerulonephritis, ${ }^{16}$ while one patient in the CARE-MS-2 study developed membranous nephritis. ${ }^{17}$ Detection, incidence, and management of glomerulonephritis in the alemtuzumab clinical development program has been reported. ${ }^{26}$

The high incidence of autoimmune disorders after alemtuzumab therapy was an unexpected safety finding. As noted by Costelloe et al, ${ }^{27}$ autoimmune thyroid diseases occur slightly more frequently among patients with $\mathrm{MS},{ }^{28}$ but the rates observed in the alemtuzumab trials far exceeded what was expected and was not observed in the control arm. The authors' search for a mechanistic explanation led them to suspect overproduction of interleukin (IL) 21. IL-21 was shown to promote proliferation of human $\mathrm{CD} 4^{+}$and $\mathrm{CD} 8^{+}$cells in in vitro culture experiments, and it was speculated that increased cell cycling was responsible for the increase in autoimmune disorders with alemtuzumab. To support this hypothesized involvement of IL-21, Costelloe et al compared serum IL-21 levels in patients who had developed autoimmunity after alemtuzumab administration with patients free of autoimmune disorders after drug administration. The authors concluded that IL-21 is a potential marker of autoimmune complications.

To reduce as far as possible the risk of autoimmune disorders with alemtuzumab treatment, it is recommended to ask the patient for a family history of autoimmunity prior to treatment. ${ }^{26}$ Patients should be informed of the common signs and symptoms of immune thrombocytic purpura, such as easy bleeding, and urged to seek medical attention should any of these symptoms 
occur. In addition, platelets and thyroid function (thyroid-stimulating hormone, free thyroxine, and free triiodothyronine) should be closely monitored. Such an approach in the CARE-MS-2 trial enabled early detection of four cases of immune thrombocytic purpura through monthly platelet monitoring, while three were detected through patient-reported signs and symptoms. ${ }^{17}$

Infusion-related reactions such as headache, rash, nausea, and pyrexia were reported in most patients receiving alemtuzumab despite prophylaxis with methylprednisolone (Table 4). However, for the most part, these events were mild to moderate in intensity, and no patients withdrew due to infusion-related reactions.

Also of note in the randomized trials, was the higher incidence of infection in alemtuzumab-treated patients ( $73 \%$ in alemtuzumab-treated patients compared to $54 \%$ in interferon beta-1a-treated patients) (Table 4). This also translated into a higher rate of serious infections (3.2\% versus $1.4 \%$, respectively) though none of these infections were considered life-threatening. One patient in the CARE-MS-2 trial discontinued therapy due to an infection (pulmonary tuberculosis). According to the summary of product characteristics, oral prophylaxis against herpes infection should be administered to all patients prior to treatment and for 1 month after each course.

\section{Outlook for alemtuzumab}

The therapeutic landscape for MS is changing rapidly. The indications and other important prescribing information for the most recently approved agents are presented in Table 5. Natalizumab, fingolimod, and alemtuzumab all have safety concerns that preclude their use in patients who do not have highly-active or aggressive disease. Indeed, natalizumab and fingolimod have almost identical indications. Although the indication for alemtuzumab has different wording, the patient population treated will likely be similar to natalizumab and fingolimod. Teriflunomide has the least restrictive indication and will probably be used in a similar way to traditional treatments such as interferon beta and glatiramer acetate. That is, it is a safe treatment appropriate for use in patients without highly active or aggressive disease, though unlike the traditional disease-modifying therapies, it offers the convenience of oral dosing. ${ }^{29}$

In addition to these new treatments, there are a number of new targeted therapies in development. ${ }^{30,31}$ Of particular interest are dimethyl fumarate (BG-12) ${ }^{32}$ and ocrelizumab. ${ }^{33}$ Such a wide choice of effective medicines is encouraging news for patients with MS.

Table 5 Comparison of the labeling for new generation multiple sclerosis treatments (as of September 29, 20I3)

\begin{tabular}{|c|c|c|c|c|}
\hline & Natalizumab & Fingolimod & Alemtuzumab & Teriflunomide \\
\hline Indication & $\begin{array}{l}\text { High disease activity despite } \\
\text { treatment with a beta interferon } \\
\text { or glatiramer acetate } \\
\text { Adult patients aged } \geq 18 \text { years } \\
\text { with rapidly evolving severe } \\
\text { relapsing-remitting multiple } \\
\text { sclerosis }^{\mathrm{b}}\end{array}$ & $\begin{array}{l}\text { High disease activity } \\
\text { despite treatment } \\
\text { with a beta interferon }^{\mathrm{a}} \\
\text { Patients with rapidly } \\
\text { evolving severe } \\
\text { relapsing-remitting } \\
\text { multiple sclerosis }^{\mathrm{b}}\end{array}$ & $\begin{array}{l}\text { Relapsing-remitting multiple sclerosis } \\
\text { with active disease defined by clinical or } \\
\text { imaging features (ie, not recommended } \\
\text { for patients with inactive disease } \\
\text { or those stable on current therapy) }\end{array}$ & $\begin{array}{l}\text { Relapsing-remitting } \\
\text { multiple sclerosis }\end{array}$ \\
\hline Posology & $\begin{array}{l}300 \mathrm{mg} \text { is administered by } \\
\text { intravenous infusion once every } \\
4 \text { weeks. Careful reassessment } \\
\text { of risk of PML required after } \\
24 \text { months of treatment }\end{array}$ & $\begin{array}{l}\text { One } 0.5 \mathrm{mg} \text { capsule } \\
\text { taken orally once } \\
\text { daily }\end{array}$ & $\begin{array}{l}\text { I2 mg/day administered by intravenous } \\
\text { infusion for two treatment courses } \\
\text { - Initial treatment course: } 12 \mathrm{mg} / \text { day for } \\
5 \text { consecutive days ( } 60 \mathrm{mg} \text { total dose) } \\
\text { - Second treatment course: } 12 \mathrm{mg} / \text { day } \\
\text { for } 3 \text { consecutive days ( } 36 \mathrm{mg} \text { total } \\
\text { dose) administered } 12 \text { months after } \\
\text { the initial treatment course }\end{array}$ & $\begin{array}{l}\text { One } 14 \mathrm{mg} \text { tablet } \\
\text { taken orally once } \\
\text { daily }\end{array}$ \\
\hline $\begin{array}{l}\text { Main special } \\
\text { warnings and } \\
\text { precautions } \\
\text { for use }\end{array}$ & PML & $\begin{array}{l}\text { Bradyarrhythmia, } \\
\text { QT interval, } \\
\text { infections }\end{array}$ & $\begin{array}{l}\text { Autoimmunity (immune thrombocytopenic } \\
\text { purpura, nephropathies, thyroid disorders, } \\
\text { cytopenias) }\end{array}$ & $\begin{array}{l}\text { Hepatic effects } \\
\text { (monitoring of alanine } \\
\text { aminotransferase } \\
\text { recommended) }\end{array}$ \\
\hline Date of approval & June 2006 & March 20II & September 2013 & August 2013 \\
\hline
\end{tabular}

by the European

Medicines Agency

Notes: a Defined as patients who have failed to respond to a full and adequate course (normally at least 12 months of treatment) of beta interferon or glatiramer acetate. Patients should have had at least one relapse in the previous year while on therapy and have at least nine T2 -hyperintense lesions in cranial magnetic resonance imaging (MRI) or at least one gadolinium-enhancing lesion. A "nonresponder" could also be defined as a patient with an unchanged or increased relapse rate or on-going severe relapses as compared to the previous year; 'two or more disabling relapses in 12 months, and with one or more gadolinium-enhancing lesions on brain MRI or a significant increase in T2 lesion load as compared to a recent MRI.

Abbreviation: PML, progressive multifocal leukoencephalopathy. 
An important aspect of long-term treatment in a disease such as MS is adherence to therapy. In this sense, the once a year pulse regimen of alemtuzumab may well prove more conducive to adherence than other therapies that require regular injections or infusions, although studies in clinical practice would be needed to confirm this potential benefit.

Although many of the new therapies have safety drawbacks, as our knowledge of risk factors and risk stratification grows, neurologists will be able to choose the most potentially safe treatment for their patients, bringing us closer to the ideal of tailored therapy. In the case of alemtuzumab, the autoimmune disorders that may be associated with treatment are manageable, and progress is being made towards a better understanding of the risk factors for such events. Altogether, alemtuzumab represents a potent addition to the armamentarium available to physicians responsible for treating MS patients.

\section{Disclosure}

The author reports no conflicts of interest in this work.

\section{References}

1. Coles AJ, Wing MG, Molyneux P, et al. Monoclonal antibody treatment exposes three mechanisms underlying the clinical course of multiple sclerosis. Ann Neurol. 1999;46(3):296-304.

2. Moreton P, Kennedy B, Lucas G, et al. Eradication of minimal residual disease in B-cell chronic lymphocytic leukemia after alemtuzumab therapy is associated with prolonged survival. J Clin Oncol. 2005;23(13):2971-2979.

3. Schnitzer TJ, Yocum DE, Michalska M, et al. Subcutaneous administration of CAMPATH-1H: clinical and biological outcomes. J Rheumatol. 1997;24(6):1031-1036.

4. Lim SH, Hale G, Marcus RE, Waldmann H, Baglin TP. CAMPATH-1 monoclonal antibody therapy in severe refractory autoimmune thrombocytopenic purpura. Br J Haematol. 1993;84(3):542-544.

5. Lockwood CM, Thiru S, Isaacs JD, Hale G, Waldmann H. Long-term remission of intractable systemic vasculitis with monoclonal antibody therapy. Lancet. 1993;341(8861):1620-1622.

6. Lockwood CM, Thiru S, Stewart S, et al. Treatment of refractory Wegener's granulomatosis with humanized monoclonal antibodies. QJM. 1996;89(12):903-912.

7. Coles AJ, Cox A, Le Page E, et al. The window of therapeutic opportunity in multiple sclerosis: evidence from monoclonal antibody therapy. J Neurol. 2006;253(1):98-108.

8. European Medicines Agency. European Public Assessment Report (Alemtuzumab). London: European Medicines Agency; 2013. Available from: http://www.ema.europa.eu/docs/en_GB/document_library/ EPAR_-_Public_assessment_report/human/003718/WC500150522. pdf. Accessed October 15, 2013.

9. Osterborg A, Dyer MJ, Bunjes D, et al. Phase II multicenter study of human CD52 antibody in previously treated chronic lymphocytic leukemia. European Study Group ofCAMPATH-1HTreatment in Chronic Lymphocytic Leukemia. J Clin Oncol. 1997;15(4):1567-1574.

10. European Medicines Agency. Summary of Product Characteristics (Alemtuzumab). London: European Medicines Agency; 2013. Available from: http://www.ema.europa.eu/docs/en_GB/document_library/ EPAR_-_Product_Information/human/003718/WC500150521.pdf. Accessed October 15, 2013.
11. Hale G, Rebello P, Brettman LR, et al. Blood concentrations of alemtuzumab and antiglobulin responses in patients with chronic lymphocytic leukemia following intravenous or subcutaneous routes of administration. Blood. 2004;104(4):948-955.

12. Brown JW, Coles AJ. Alemtuzumab: evidence for its potential in relapsing-remitting multiple sclerosis. Drug Des Devel Ther. 2013;7: 131-138.

13. Cox AL, Thompson SA, Jones JL, et al. Lymphocyte homeostasis following therapeutic lymphocyte depletion in multiple sclerosis. Eur $J$ Immunol. 2005;35(11):3332-3342.

14. Jones JL, Anderson JM, Phuah CL, et al. Improvement in disability after alemtuzumab treatment of multiple sclerosis is associated with neuroprotective autoimmunity. Brain. 2010;133(Pt 8): 2232-2247.

15. CAMMS223 Trial Investigators, Coles AJ, Compston DA, et al. Alemtuzumab vs interferon beta-1a in early multiple sclerosis. $N$ Engl J Med. 2008;359(17):1786-1801.

16. Cohen JA, Coles AJ, Arnold DL, et al; CARE-MS I investigators. Alemtuzumab versus interferon beta 1a as first-line treatment for patients with relapsing-remitting multiple sclerosis: a randomised controlled phase 3 trial. Lancet. 2012;380(9856):1819-1828.

17. Coles AJ, Twyman CL, Arnold DL, et al; CARE-MS II investigators. Alemtuzumab for patients with relapsing multiple sclerosis after disease-modifying therapy: a randomised controlled phase 3 trial. Lancet. 2012;380(9856):1829-1839.

18. Filippini G, Del Giovane C, Vacchi L, et al. Immunomodulators and immunosuppressants for multiple sclerosis: a network meta-analysis. Cochrane Database Syst Rev. 2013;6:CD008933.

19. Galetta SL, Markowitz C, Lee AG. Immunomodulatory agents for the treatment of relapsing multiple sclerosis: a systematic review. Arch Intern Med. 2002;162(19):2161-2169.

20. Panitch H, Goodin DS, Francis G, et al; EVIDENCE Study Group. Randomized, comparative study of interferon beta-1a treatment regimens in MS: The EVIDENCE Trial. Neurology. 2002;59(10): 1496-1506.

21. Schwid SR, Panitch HS. Full results of the Evidence of Interferon Dose-Response-European North American Comparative Efficacy (EVIDENCE) study: a multicenter, randomized, assessor-blinded comparison of low-dose weekly versus high-dose, high-frequency interferon beta-1a for relapsing multiple sclerosis. Clin Ther. 2007;29(9): 2031-2048.

22. Polman CH, O'Connor PW, Havrdova E, et al; AFFIRM Investigators. A randomized, placebo-controlled trial of natalizumab for relapsing multiple sclerosis. N Engl J Med. 2006;354(9):899-910.

23. Moreau T, Thorpe J, Miller D, et al. Preliminary evidence from magnetic resonance imaging for reduction in disease activity after lymphocyte depletion in multiple sclerosis. Lancet. 1994;344(8918): 298-301.

24. Paolillo A, Coles AJ, Molyneux PD, et al. Quantitative MRI in patients with secondary progressive MS treated with monoclonal antibody Campath 1H. Neurology. 1999;53(4):751-757.

25. Hirst CL, Pace A, Pickersgill TP, et al. Campath 1-H treatment in patients with aggressive relapsing remitting multiple sclerosis. J Neurol. 2008;255(2):231-238.

26. Wynn D, Arnold DL, Coles AJ, et al. Detection, incidence, and management of glomerulonephritis in the alemtuzumab clinical development program. Poster P597 presented at: 29th Congress of the European Committee for Research and Treatment in Multiple Sclerosis (ECTRIMS); October 2-5, 2013; Copenhagen, Denmark.

27. Costelloe L, Jones J, Coles A. Secondary autoimmune diseases following alemtuzumab therapy for multiple sclerosis. Expert Rev Neurother. 2012;12(3):335-341.

28. Niederwieser G, Buchinger W, Bonelli RM, et al. Prevalence of autoimmune thyroiditis and non-immune thyroid disease in multiple sclerosis. J Neurol. 2003;250(6):672-675.

29. Oh J, O'Connor PW. An update of teriflunomide for treatment of multiple sclerosis. Ther Clin Risk Manag. 2013;9:177-190. 
30. Deiß A, Brecht I, Haarmann A, Buttmann M. Treating multiple sclerosis with monoclonal antibodies: a 2013 update. Expert Rev Neurother. 2013;13(3):313-335.

31. Ali R, Nicholas RS, Muraro PA. Drugs in development for relapsing multiple sclerosis. Drugs. 2013;73(7):625-650.

32. Gold R, Kappos L, Arnold DL, et al; DEFINE Study Investigators. Placebo-controlled phase 3 study of oral BG-12 for relapsing multiple sclerosis. N Engl J Med. 2012;367(12):1098-1107.
33. Kappos L, Li D, Calabresi PA, et al. Ocrelizumab in relapsing-remitting multiple sclerosis: a phase 2, randomised, placebo-controlled, multicentre trial. Lancet. 2011;378(9805):1779-1787.

Journal of Inflammation Research

\section{Publish your work in this journal}

The Journal of Inflammation Research is an international, peer-reviewed open-access journal that welcomes laboratory and clinical findings on the molecular basis, cell biology and pharmacology of inflammation including original research, reviews, symposium reports, hypothesis formation and commentaries on: acute/chronic inflammation; mediators of inflamma-
Dovepress

tion; cellular processes; molecular mechanisms; pharmacology and novel anti-inflammatory drugs; clinical conditions involving inflammation. The manuscript management system is completely online and includes a very quick and fair peer-review system. Visit http://www.dovepress.com/ testimonials.php to read real quotes from published authors.

\footnotetext{
Submit your manuscript here: http://www.dovepress.com/journal-of-inflammation-research-journal
} 